Original research article

\title{
The relationship between brain abnormalities and autistic psychopathology in pervasive developmental disorders
}

\author{
Andrea Efremova ${ }^{1,3 *}$, Jiri Lisy ${ }^{2,5}$, Michal Hrdlicka ${ }^{1,4}$ \\ ${ }^{1}$ University Hospital Motol and Charles University, Second Faculty of Medicine, Department of Child Psychiatry, Prague, Czech Republic \\ ${ }^{2}$ University Hospital Motol and Charles University, Second Faculty of Medicine, Department of Radiology, Prague, Czech Republic \\ ${ }^{3}$ Charles University, First Faculty of Medicine, Prague, Czech Republic \\ ${ }^{4}$ Masaryk University, Faculty of Arts, Department of Psychology, Brno, Czech Republic \\ ${ }^{5}$ Hospital Na Homolce, Department of Radiology, Prague, Czech Republic
}

\section{Abstract}

The aim of the present research has been to determine whether there is a relationship between brain abnormalities found on magnetic resonance imaging (MRI) and autistic psychopathology.

A retrospective analysis covering a period between 1998 and 2015 included 489 children with autism (404 boys, 85 girls; average age $8.0 \pm 4.2$ years) who underwent an MRI of the brain. For clinical diagnosis of autism, the International Classification of Diseases, 10th revision (ICD-10), was used. Autistic psychopathology was evaluated by means of the Autism Diagnostic Interview - Revised. The Spearman nonparametric correlation analysis and chi-square test were used to examine the possible relationships between variables.

The group of autistic children did not manifest a statistically significant correlation between the parameters examined on MRI and autistic psychopathology. A correlation between other cysts and repetitive behavior was significant only at trend level $(P=0.054)$. Gliosis of the brain was significantly more frequent in autistic children with mental retardation than in children without mental retardation $(14.1 \%$ vs. $7.4 \% ; P=0.028)$. Nonmyelinated areas in the brain were significantly more frequent in autistic children with autistic regression than in children without autistic regression $(29.9 \%$ vs. $15.7 \% ; P=0.008)$. Mental retardation was significantly more frequent in autistic children with autistic regression than in children without regression $(73.2 \%$ vs. $52.5 \% ; P=0.002)$.
\end{abstract}

Our research study did not reveal a statistically significant correlation of brain abnormalities on MRI with autistic psychopathology.

Keywords: Autism; Brain; MRI; Psychopathology

\section{Highlights:}

- Magnetic resonance imaging is a powerful tool for researching the autistic brain.

- The connection between brain abnormalities and autism in children is already proven.

- Autism is linked to atypicalities in corpus callosum, caudate nucleus, and cerebellum.

- Psychopathological manifestations can be correlated with specific brain structures.

- Clinical endophenotypes of ASD may be associated with gliosis or nonmyelinated areas.

\section{Introduction}

With the advent of modern magnetic resonance imaging (MRI), in recent decades the opportunity has arisen to study brain morphology and pathology with high accuracy. The MRI technology has gained its place in the clinical and scientific fields due to its absence of ionizing radiation, excellent soft tissue imaging, and better contrast sensitivity and spatial resolution compared with computed tomography (CT). To research the autistic brain, structural MRI (sMRI), functional MRI (fMRI), and tractography based on diffuse tensor imaging (DTI) are used. The aim of this retrospective study is to de- termine whether there is a relationship between MRI findings and autistic symptomatology.

Based on the current state of knowledge about the autistic brain, we can start establishing the first consistent correlates between psychopathological manifestations and individual brain structures, areas, and connections, in the following way. (1) Disruption of socio-emotional interactions is associated with frontotemporal regions and the amygdala (Allison et al., 2000; Boddaert et al., 2004; Juranek et al., 2006; Nacewicz et al., 2006; Rojas et al., 2006). (2) Disruption of social communication and speech is associated with the Broca's and Wernicke's areas (Redcay, 2008). (3) Repetitive and stereotyped behaviors are associated with the caudate nucleus (Hollander

\footnotetext{
* Corresponding author: Andrea Efremova, University Hospital Motol and Charles University, Second Faculty of Medicine, Department of Child Psychiatry, V Uvalu 84, 15006 Prague, Czech Republic; e-mail: andrea.efremova@fnmotol.cz http://doi.org/10.32725/jab.2021.009

Submitted: 2020-10-26 • Accepted: 2021-04-06 • Prepublished online: 2021-04-14

J Appl Biomed 19/2: 91-96 • EISSN 1214-0287 • ISSN 1214-021X

(c) 2021 The Authors. Published by University of South Bohemia in České Budějovice, Faculty of Health and Social Sciences.

This is an open access article under the CC BY-NC-ND license.
} 
et al., 2005; Langen et al., 2009; Sears et al., 1999) and the orbitofrontal cortex (McAlonan et al., 2002). Overall, there is a strong relationship between neuroanatomical abnormalities and functional socio-cognitive deficits, which are typical of autism spectrum disorders (ASD).

\section{Materials and methods}

Our retrospective analysis involved a sample of children who had attended a diagnostic examination focused on autism at the Department of Child Psychiatry of the Second Faculty of Medicine at Charles University and University Hospital Motol between the years 1998 and 2015. The parents of our patients provided an informed consent to a routine brain MRI as part of the examination, and most of the examinations were performed under general anesthesia. The study was approved by the Ethics Committee of University Hospital Motol under reference number EK-124/17.

From 1998 to 2015 , a total of 489 children were diagnosed with pervasive developmental disorder (404 boys, 85 girls). The mean age in the group was $8.0 \pm 4.2$ years (range $1.7-26.0$ years). The upper age limit was 26 years because in a few exceptional cases, adult patients were examined within the observed period of time as well, using the same diagnostic tools as those used for child patients. Rather than excluding the several adult patients from the study sample, we decided to utilize the valuable data obtained from their examination and include them in the study despite their age. The diagnoses, based on ICD10, included 314 patients with childhood autism, 68 patients with atypical autism, 82 patients with Asperger syndrome, and 4 patients with other childhood disintegrative disorders. Two patients were diagnosed with Rett syndrome, 6 patients with other pervasive developmental disorders, and 7 patients with a pervasive developmental disorder not otherwise specified. Data on intellectual functioning were available in 322 out of 489 autistic patients ( $65.8 \%$ of the autistic group). Out of 322 children, 189 were diagnosed with mental retardation (58.7\%).

The International Classification of Diseases, 10th revision (1996), was used for the clinical diagnosis of ASD. Each patient was examined by an experienced child psychiatrist. Between 1998 and 1999, the assessment of the patient's condition was supported by the Childhood Autism Rating Scale (Schopler et al., 1980). Starting in 2000, the third version of the Autism Diagnostic Interview - Revised (ADI-R) was used for assessments (Lord et al., 1994); and from 2012 onwards, the Autism Diagnostic Observation Schedule - Generic (Lord et al., 2000) was added to diagnostic procedures. Both methods continue to be used at our department to this day. The assessment of the patient's intellect was performed using the Gesell Developmental Schedules in younger children and the Stanford-Binet Intelligence Scales in older children.

The research was carried out in interdisciplinary collaboration with the Department of Radiology of the Second Faculty of Medicine at Charles University and University Hospital Motol. MRI scans were acquired using a 1.5 Tesla Philips Gyroscan ACS 15NT and later using a 1.5 Tesla Philips Ingenia scanner. The imaging protocol consisted of four pulse sequences: (1) T2 turbo spin echo (T2/TSE) in the axial plane, (2) fluid-attenuated inversion recovery (FLAIR) in the axial plane, (3) T1 turbo spin echo (T1/IR-TSE) in the coronal plane, and (4) T1 spin echo (T1/SE) in the sagittal plane. The acquired brain scans were again assessed and subsequently categorized according to the severity of the pathology. The assessment and catego- rization of the findings were performed by an experienced neuroradiologist (JL). Between 1998 and 2002, the scans were assessed using hard copies; and after 2003, digital images were used. The radiologic assessments of pathologies were divided into three categories: (1) normal, (2) benign pathology (e.g., mega cisterna magna, gliosis, arachnoid cysts), and (3) severe pathology (e.g., septo-optic dysplasia, pilocytic astrocytoma, cavernoma, mesial temporal sclerosis). All digital MRI images were assessed again within this study. Hard copy MRI scans were no longer available for reassessment, therefore, only some parameters (severe pathologies, gliosis, arachnoid cysts, and other cysts), once assessed by the same radiologist (JL), could be transferred to the current study.

The data collection matrix devised for the purpose of this research included: (1) assessment and categorization of MRI scans, (2) ADI-R assessment (Autism Diagnostic Interview Revised), (3) presence of autistic regression, and (4) presence of mental retardation.

Statistical analysis was performed using the Statistical Package for the Social Sciences (IBM SPSS, version 22.0). Descriptive statistics was used. Spearman nonparametric correlation analysis was used to evaluate the relationship between brain abnormalities on MRI and autistic psychopathology. A chi-square test was used to compare the incidence of mental retardation and autistic regression with the incidence of pathology on MRI. Only MRI findings with a total number $>10$ were included in the assessment.

\section{Theory}

The above-described connections of specific psychopathological manifestations with individual areas of the brain are based on the results of research studies. However, the situation is different in the field of routine MRI. Major organizations such as the American Academy of Child and Adolescent Psychiatry (Volkmar et al., 2014) or the National Institute for Health and Care Excellence (NICE, 2011) do not recommend routine brain MRI as part of diagnostic procedures for autism.

Not much is known about the utility of routine brain MRI either. There are only a few research studies that address the benefits of routine brain MRI. We identified only six studies, with $33,55,70,70,85$, and 782 children, respectively. Two of the six studies were methodologically compromised by having examined some of the children by $\mathrm{CT}$ and others by MRI; nevertheless, both studies reported negative results (Kosinovsky et al., 2005; Shevell et al., 2001). Challman et al. (2003) reported central nervous system (CNS) abnormalities in 17 out of 70 children (24\%). None of the abnormalities required intervention, and only one MRI scan (in a patient with multiple cortical tubers) led to a specific diagnosis. Battaglia and Carey (2006) found abnormalities in 2 out of 85 children $(2.4 \%)$. In one case, it was a relative macrocrania with right lateral ventricular heterotopia, with no manifestation of neurological symptoms. The other case involved partial agenesis of the corpus callosum (CC) with right cerebellar hemisphere hypoplasia. Zeglam et al. (2015) found abnormalities in 26 out of 782 autistic children (3.3\%). These abnormalities included 8 subjects with leukodystrophy, 4 with periventricular leukomalacia, 3 with brain atrophies, 3 with CC agenesis, 2 with tuberous sclerosis, 2 with vascular changes, and one each with a pineoblastoma, a cerebellar angioma, a cerebellar hypoplasia, and a neuroepithelial cyst. Minor findings or variants of the norm (ventricular dilatation, enlarged Virchow-Robin space, arachnoid cysts) were not classified as abnormalities. However, the study of this team raises some concerns about methodology, e.g., the age of the youngest subject in the autistic 
children sample is given as one month (sic) and the diagnostic procedures are not further specified. Ming et al. (2016) reported parenchymal abnormalities in 8 out of 55 children (14.6\%). These abnormalities included 2 children with type 1 Chiari malformation; 1 child with hamartoma and 6 caféau-lait spots, not classified as neurofibromatosis; 1 child with enlarged Virchow-Robin space; 1 child with venous angioma in the right frontal lobe; and 3 children with abnormal white matter signals (classified as non-specific changes).

\section{Results}

In the Czech Republic, some hospitals (including ours) perform routine brain MRI as part of diagnostic procedures for autism. In the first, already published analysis of our data, we showed that CC hypoplasia was significantly more common in autistic children compared with the control group (13.7\% vs. 0\%) (Lisy et al., 2019).

In the autistic group, no statistically significant correlation was found between the monitored parameters on MRI and autistic psychopathology as measured by the ADI-R (Table 1). The correlation between other cysts and repetitive behavior was significant only at the trend level $(P=0.054)$. Gliosis was significantly more common in autistic children with mental retardation compared to children without mental retardation $(P=0.028)$. Nonmyelinated areas of the brain were significantly more common in autistic children with autistic regression compared to children without regression $(P=0.008)$. For details, see Table 2 . It is worth noting that mental retardation was significantly more common in autistic children with autistic regression compared to children without regression $(73.2 \%$ vs. $52.5 \%$; chi $^{2}=9.893 ; \mathrm{df}=1 ; P=0.002$ ).

Table 1. Correlation between MRI pathologies and scores of the Autism Diagnostic Interview - Revised

\begin{tabular}{|c|c|c|c|c|c|}
\hline Finding & & $\begin{array}{c}\text { Score ADI-R } \\
\text { SI }\end{array}$ & $\begin{array}{c}\text { Score ADI-R } \\
\text { VC }\end{array}$ & $\begin{array}{c}\text { Score ADI-R } \\
\text { NVC }\end{array}$ & $\begin{array}{c}\text { Score ADI-R } \\
\text { RB }\end{array}$ \\
\hline \multirow{2}{*}{ Gliosis } & $R$ & 0.030 & 0.019 & 0.114 & 0.016 \\
\hline & $N$ & 335 & 233 & 208 & 333 \\
\hline \multirow{2}{*}{ Arachnoid cysts } & $R$ & 0.036 & 0.099 & 0.013 & 0.066 \\
\hline & $N$ & 335 & 233 & 208 & 333 \\
\hline \multirow{2}{*}{ Other cysts } & $R$ & 0.006 & 0.005 & 0.055 & 0.106 \\
\hline & $N$ & 335 & 233 & 208 & 333 \\
\hline \multirow{2}{*}{ Nonmyelinated areas } & $R$ & 0.092 & 0.053 & 0.072 & 0.035 \\
\hline & $N$ & 285 & 198 & 159 & 283 \\
\hline \multirow{2}{*}{ CC hypoplasia } & $R$ & 0.011 & 0.018 & 0.047 & 0.092 \\
\hline & $N$ & 285 & 198 & 159 & 283 \\
\hline \multirow{2}{*}{ Mega cisterna magna } & $R$ & 0.061 & 0.024 & 0.095 & 0.067 \\
\hline & $N$ & 285 & 198 & 159 & 283 \\
\hline
\end{tabular}

$R$ - Spearman correlation coefficient; $N$ - number of patients; ${ }^{*} p<0.05 ;{ }^{* *} p<0.01$. ADI-R - Autism Diagnostic Interview - Revised; SI - social interaction; VC - verbal communication; NVC - nonverbal communication; RB - repetitive behavior and interests.

Table 2. Relationships of MRI findings to other psychopathologies

\begin{tabular}{|c|c|c|c|c|}
\hline MRI finding & Presence of the MRI finding & Mental retardation absent & Mental retardation present & Statistics \\
\hline \multirow{3}{*}{ Gliosis } & NO & $174(92.6 \%)$ & $219(85.9 \%)$ & \multirow{2}{*}{$\begin{array}{c}\mathrm{chi}^{2}=4.810 ; \mathrm{df}=1 ; \\
P=0.028\end{array}$} \\
\hline & YES & $14(7.4 \%)$ & $36(14.1 \%)$ & \\
\hline & & Autistic regression absent & Autistic regression present & \\
\hline \multirow{2}{*}{$\begin{array}{l}\text { Nonmyelinated areas of } \\
\text { the brain }\end{array}$} & NO & $214(84.3 \%)$ & $47(70.1 \%)$ & \multirow{2}{*}{$\begin{array}{c}\mathrm{chi}^{2}=6.938 ; \mathrm{df}=1 ; \\
P=0.008\end{array}$} \\
\hline & YES & $40(15.7 \%)$ & $20(29.9 \%)$ & \\
\hline
\end{tabular}

\section{Discussion}

None of the studies on the etiological utility of MRI discussed in the theoretical section (Battaglia and Carey, 2006; Challman et al., 2003; Kosinovsky et al., 2005; Ming et al., 2016; Shevell et al., 2001; Zeglam et al., 2015) attempted to correlate MRI findings with psychopathology, which makes discussion diffcult. The fact that CC hypoplasia did not correlate with psychopathology in our study means that it is a trait marker rather than a state marker. At present, diagnostic procedures rely on a clinical description of ASD using diagnostic manuals for clinical interview (ADI-R) and clinical observation (ADOS). While these diagnostic manuals (ADI-R, ADOS) are very useful and reliable examination tools, they do not address the neurobiological nature of the disease. Validated biomarkers are urgently needed to detect ASD at the earliest possible stage, establish a prognosis, and start timely intervention. Accordingly, the role of neuroimaging methods in the study of the autistic brain appears to be shifting from the scientific setting to the clinical 
one. In our previous study (Lisy et al., 2019), we reported that CC hypoplasia could be one of the possible biomarkers in suspected ASD. However, the clinical application of neuroimaging approaches remains dependent on their validation in the clinical setting, which requires large independent research samples obtained both in the clinical setting and in the real world. If the validation is successful, these new approaches can one day become invaluable in the diagnostic procedures, treatment, and description of ASD.

In our present study, we identified an association of mental retardation with autistic regression. Several studies have reported that autistic children with a history of developmental regression show more severe autistic symptoms, especially in relation to the level of intellectual functioning, verbal abilities, and adaptation skills, compared to autistic children without developmental regression (Bernabei et al., 2007; Rogers and DiLalla, 1990; Tuchman and Rapin, 1997). Other studies either reported differences in only a few functional areas (Brown and Prelock, 1995; Kobayashi and Murata, 1998), or found no differences between the groups at all (Davidovitch et al., 2000; Tolbert et al., 2001; Werner et al., 2005), or even reported higher performance in children with developmental regression (Harper, 1975). The presence of autistic regression is assessed retrospectively from a clinical interview with the child's parents and/or from provided home videos, where regression is determined based on obvious major signs of skill loss. Some authors (Jones et al., 2014; Ozonoff et al., 2018; Pearson et al., 2018) regard autistic regression diagnosed in this way as the "tip of the iceberg" and consider the presence of autistic regression in ASD as the rule rather than the exception. Current research focuses on the prospective study of autistic regression, which allows for the mapping of an even subtler loss of previously acquired skills. In their article, Ozonoff and Iosif (2019) discuss the validity of previous autistic regression research studies that do not include the influence of etiological and environmental factors involved in the development of ASD. Subtypes of autism must be identified first and only then is it possible to subsume under them the individual genetic variations (Geschwind, 2011) that lead to the manifestation of differences in neurobiological brain development in early childhood (Konopka et al., 2012).

Current studies report a significant association of mental retardation with epilepsy in ASD. The severity of mental retardation, female sex, and older age are risk factors for comorbid epilepsy in ASD (Amiet et al., 2008; Hrdlicka et al., 2004; Viscidi et al., 2013). The relationship between autistic regression and epilepsy is still unclear, but some results suggest that the higher the incidence of epilepsy in the research sample, the greater the probability of a significant link between them (Hrdlicka, 2008).

It is difficult in general to find a correlation between autistic symptoms and/or degree of their severity with objective neurophysiological parameters. Several studies found a positive relationship between EEG abnormalities and the severity of autism (Ekinci et al., 2010; Mulligan and Trauner, 2014), while other studies found no relationship (Hartley-McAndrew and Weinstock, 2010; Hrdlicka et al., 2004). Some studies reported a significant correlation of EEG abnormalities with lower IQ (Tuchman, 2017; Yasuhara, 2010), but other studies did not confirm this finding (Baird et al., 2006; Hrdlicka et al., 2004). EEG abnormalities are a sign of brain dysfunction, but it is not clear whether they are responsible for autistic traits (Mulligan and Trauner, 2014). Furthermore, some studies found abnormal skin conductance responses in autism (Joseph et al., 2008; Kylliainen and Hietanen, 2006), while others did not (Ben Shalom et al., 2006). Similarly, our present study does not find a significant correlation of CC hypoplasia with psychopathology.

According to the results of our study, gliosis of the brain is more common in autistic children with mental retardation than in children without mental retardation. In other research studies, gliosis of the brain is associated with autism (Fezer et al., 2017; Steiner et al., 2003; Wegiel et al., 2010) but also with mental retardation alone (da Rocha et al., 2006). Gliosis does not constitute a disease of its own, rather, it is the result of a repair mechanism which is triggered by early brain damage. Premature birth, perinatal asphyxia, and low birth weight are generally risk factors for early brain damage (Fezer et al., 2017). Severe hypoxic-ischemic brain damage in premature infants is manifested primarily as damage to gray matter and brainstem structures. Mild to moderate cases are usually manifested as either intraventricular hemorrhage or periventricular leukomalacia (Barkovich and Sargent, 1995; Barkovich et al., 1995). The location and severity of the damage then determine the resulting physical and mental condition of the individual.

Based on the results of our study, we identified a correlation between other cysts and repetitive behavior which was significant only at the trend level. The term "other cysts" covers the following: pineal cysts, subependymal cysts in the lateral ventricles and foramen Monroi, septum pellucidum cysts, choroidal cysts, and cystic encephalomalacia. Studies of pineal cysts show that the prevalence of pineal cysts is significantly higher in autistic children compared with non-autistic children (Coelho et al., 2020). One of the proposed biological causes of autism is dysfunction of the pineal gland, involving a deficiency of its principal hormone, melatonin. The resulting clinical sign of sleep disorder is often associated with ASD. Dysfunction of the pineal gland is also related to abnormal metabolism of N-dimethyltryptamine, which could explain the abnormal neuroplasticity and neuronal distribution that are present in some cases of autism (Bedford et al., 2016). Subependymal cysts were found to be closely associated with developmental delay and developmental disability, ADHD and ASD in particular, while the higher the extent of subependymal cysts, the higher the risk of neurodevelopmental delay (Chang et al., 2018). The pathogenesis of subependymal cysts in the lateral ventricles is unclear, but histological studies identified macrophages lining the cysts, which indicates preexisting malacia caused by old hemorrhage, hypoxia, metabolic disease, and viral infection insults of the germinal matrix (Malinger et al., 2002; Shaw and Alvord, 1974). On the other hand, it is interesting that studies of the choroid plexus do not indicate any developmental delay (DiPietro, 2011). Generally, the discrepancy between various cysts may suggest the importance of anatomical location and the extent of the cysts because of their effect on neurodevelopment.

The modern MRI neuroimaging method is an excellent diagnostic tool that enabled us to identify brain abnormalities often associated with autism. However, the correlation of MRI findings with autistic symptomatology did not deliver a strong yield, and the interpretation of our negative results is problematic owing to the huge phenotypic heterogeneity of ASD. Most of the abnormalities found are regarded as signs of brain dysgenesis, but their role in the psychopathology of autism requires further research. 


\section{Conclusions}

Our research study did not reveal a statistically significant correlation of brain abnormalities on MRI with autistic psychopathology.

\section{Acknowledgements}

This publication was written within the Charles University Progress program no. Q15, "Life trajectories, lifestyles, and quality of life from the perspective of individual adaptation and the relationship between actors and institutions", and was supported by the Ministry of Health of the Czech Republic, research grant no. NV18-04-00085, and the project for the Long-Term Conceptual Development of Research Organizations, project no. 00064203, at the University Hospital Motol. The funding sources had no involvement in the study design; in the collection, analysis, and interpretation of data; and in the writing of the report.

The study has been proofread by an experienced copyeditor, Marketa Gregorova.

\section{Author contributions}

AE: drafted the manuscript and collected data; JL: assessed the MRI scans, commented on the manuscript, and contributed to the design of the study; $\mathrm{MH}$ : conceived the study, performed statistical analysis, and commented on the manuscript. All authors have approved the final article.

\section{Conflict of interests}

The authors state that there are no conflicts of interests regarding the publication of this article.

\section{References}

Allison T, Puce A, McCarthy G (2000). Social perception from visual cues: role of the STS region. Trends Cogn Sci 4(7): 267-278. DOI: 10.1016/s1364-6613(00)01501-1.

Amiet C, Gourfinkel-An I, Bouzamondo A, Tordjman S, Baulac M, Lechat P, et al. (2008). Epilepsy in autism is associated with intellectual disability and gender: evidence from a metaanalysis. Biol Psychiatry 64(7): 577-582. DOI: 10.1016/j. biopsych.2008.04.030.

Baird G, Robinson RO, Boyd S, Charman T (2006). Sleep electroencephalograms in young children with autism with and without regression. Dev Med Child Neurol 48(7): 604-608. DOI: $10.1017 /$ S0012162206001265.

Barkovich AJ, Sargent SK (1995). Profound asphyxia in the premature infant: imaging findings. AJNR Am J Neuroradiol 16(9): 1837-1846.

Barkovich AJ, Westmark K, Partridge C, Sola A, Ferriero DM (1995). Perinatal asphyxia: MR findings in the first 10 days. AJNR Am J Neuroradiol 16(3): 427-438.

Battaglia A, Carey JC (2006). Etiologic yield of autistic spectrum disorders: a prospective study. Am J Med Genet C Semin Med Genet 142C(1): 3-7. DOI: 10.1002/ajmg.c.30076.

Bedford R, Jones EJ, Johnson MH, Pickles A, Charman T, Gliga T (2016). Sex differences in the association between infant markers and later autistic traits. Mol Autism 7: 21. DOI: 10.1186/s13229016-0081-0.

Ben Shalom D, Mostofsky SH, Hazlett RL, Goldberg MC, Landa RJ, Faran Y, et al. (2006). Normal physiological emotions but differences in expression of conscious feelings in children with high-functioning autism. J Autism Dev Disord 36(3): 395-400. DOI: 10.1007/s10803-006-0077-2.
Bernabei P, Cerquiglini A, Cortesi F, D’Ardia C (2007). Regression versus no regression in the autistic disorder: developmental trajectories. J Autism Dev Disord 37(3): 580-588. DOI: 10.1007/ s10803-006-0201-3

Boddaert N, Chabane N, Gervais H, Good CD, Bourgeois M, Plumet $\mathrm{MH}$, et al. (2004). Superior temporal sulcus anatomical abnormalities in childhood autism: a voxel-based morphometry MRI study. Neuroimage 23(1): 364-369. DOI: 10.1016/j. neuroimage.2004.06.016.

Brown J, Prelock PA (1995). Brief report: the impact of regression on language development in autism. J Autism Dev Disord 25(3): 305-309. DOI: 10.1007/BF02179291.

Challman TD, Barbaresi WJ, Katusic SK, Weaver A (2003). The yield of the medical evaluation of children with pervasive developmental disorders. J Autism Dev Disord 33(2): 187-192. DOI: 10.1023/a:1022995611730.

Chang H, Tsai C-M, Hou C-Y, Tseng S-H, Lee J-C, Tsai M-L (2018). Multiple subependymal pseudocysts in neonates play a role in later attention deficit hyperactivity and autistic spectrum disorder. J Formos Med Assoc 118(3): 692-699. DOI: 10.1016/j. jfma.2018.08.007.

Coelho AM, Gouveia F, Costa M (2020). Is the pineal cyst a relevant issue for autism? J Neurol Neurobiol 6(3). DOI: 10.16966/23797150.166.

da Rocha AF, da Costa Leite C, Rocha FT, Massad E, Cerri GG, de Oliveira Angelotti SA, et al. (2006). Mental retardation: a MRI study of 146 Brazilian children. Arq Neuropsiquiatr 64(2A): 186-192. DOI: 10.1590/s0004-282x2006000200003.

Davidovitch M, Glick L, Holtzman G, Tirosh E, Safir MP (2000). Developmental regression in autism: maternal perception. J Autism Dev Disord 30(2): 113-119. DOI: 10.1023/a:1005403421141.

DiPietro JA, Cristofalo EA, Voegtline KM, Crino J (2011). Isolated prenatal choroid plexus cysts do not affect child development. Prenat Diagn 31(8): 745-749. DOI: 10.1002/pd.2757.

Ekinci O, Arman AR, Işik U, Bez Y, Berkem M (2010). EEG abnormalities and epilepsy in autistic spectrum disorders: clinical and familial correlates. Epilepsy Behav 17(2): 178-182. DOI: 10.1016/j.yebeh.2009.11.014.

Fezer GF, Matos MB, Nau AL, Zeigelboim BS, Marques JM, Liberalesso PB (2017). Perinatal features of children with autism spectrum disorder. Rev Paul Pediatr 35(2): 130-135. DOI: 10.1590/1984-0462/;2017;35;2;00003.

Geschwind DH (2011). Genetics of autism spectrum disorders. Trends Cogn Sci 15(9): 409-416.

Harper J (1975). Age and type of onset as critical variables in early infantile autism. J Autism Child Schizophr 5(1): 25-36. DOI: 10.1016/j.tics.2011.07.003.

Hartley-McAndrew M, Weinstock A (2010). Autism spectrum disorder: correlation between aberrant behaviors, EEG abnormalities and seizures. Neurol Int 2(1): e10. DOI: 10.4081/ ni.2010.e10.

Hollander E, Anagnostou E, Chaplin W, Esposito K, Haznedar MM, Licalzi E, et al. (2005). Striatal volume on magnetic resonance imaging and repetitive behaviors in autism. Biol Psychiatry 58(3): 226-232. DOI: 10.1016/j.biopsych.2005.03.040.

Hrdlicka M (2008). EEG abnormalities, epilepsy and regression in autism: a review. Neuro Endocrinol Lett 29(4): 405-409.

Hrdlicka M, Komarek V, Propper L, Kulisek R, Zumrova A, Faladova L, et al. (2004). Not EEG abnormalities but epilepsy is associated with autistic regression and mental functioning in childhood autism. Eur Child Adolesc Psychiatry 13(4): 209-213. DOI: 10.1007/s00787-004-0353-7.

Jones, EJ, Gliga T, Bedford R, Charman T, Johnson MH (2014). Developmental pathways to autism: a review of prospective studies of infants at risk. Neurosci Biobehav Rev 39: 1-33. DOI: 10.1016/j.neubiorev.2013.12.001.

Joseph RM, Ehrman K, McNally R, Keehn B (2008). Affective response to eye contact and face recognition ability in children with ASD. J Int Neuropsychol Soc 14(6): 947-955. DOI: 10.1017/ S1355617708081344.

Juranek J, Filipek PA, Berenji GR, Modahl C, Osann K, Spence MA (2006). Association between amygdala volume 
and anxiety level: magnetic resonance imaging (MRI) study in autistic children. J Child Neurol 21(12): 1051-1058. DOI: $10.1177 / 7010.2006 .00237$.

Kobayashi R, Murata T (1998). Setback phenomenon in autism and longterm prognosis. Acta Psychiatr Scand 98(4): 296-303. DOI: 10.1111/j.1600-0447.1998.tb10087.x.

Konopka G, Wexler E, Rosen E, Mukamel Z, Osborn GE, Chen L, et al. (2012). Modeling the functional genomics of autism using human neurons. Mol Psychiatry 17(2): 202-214. DOI: 10.1038/ mp.2011.60.

Kosinovsky B, Hermon S, Yoran-Hegesh R, Golomb A, Senecky Y, Goez H, Kramer U (2005). The yield of laboratory investigations in children with infantile autism. J Neural Transm 112(4): 587-596. DOI: 10.1007/s00702-004-0198-8.

Kylliainen A, Hietanen JK (2006). Skin conductance responses to another person's gaze in children with autism. J Autism Dev Disord 36(4): 517-525. DOI: 10.1007/s10803-006-0091-4.

Langen M, Schnack HG, Nederveen H, Bos D, Lahuis BE, de Jonge MV, et al. (2009). Changes in the developmental trajectories of striatum in autism. Biol Psychiatry 66(4): 327-333. DOI: 10.1016/j.biopsych.2009.03.017.

Lisy J, Efremova A, Hrdlicka M (2019). The yield of structural magnetic resonance imaging in autism spectrum disorders. Biomed Pap Med Fac Univ Palacky Olomouc Czech Repub 163(4): 374-378. DOI: 10.5507/bp.2018.074.

Lord C, Risi S, Lambrecht L, Cook EH, Jr., Leventhal BL, DiLavore PC, et al. (2000). The autism diagnostic observation schedule generic: a standard measure of social and communication deficits associated with the spectrum of autism. J Autism Dev Disord 30(3): 205-223.

Lord C, Rutter M, Le Couteur A (1994). Autism diagnostic interviewrevised: a revised version of a diagnostic interview for caregivers of individuals with possible pervasive developmental disorders. J Autism Dev Disord 24(5): 659-685. DOI: 10.1007/BF02172145.

Malinger G, Lev D, Ben Sira L, Kidron D, Tamarkin M, LermanSagie T (2002). Congenital periventricular pseudocysts: prenatal sonographic appearance and clinical implications. Ultrasound Obstet Gynecol 20(5): 447-451. DOI: 10.1046/j.14690705.2002.00840.x.

McAlonan GM, Daly E, Kumari V, Critchley HD, van Amelsvoort T, Suckling J, et al. (2002). Brain anatomy and sensorimotor gating in Asperger's syndrome. Brain 125(Pt 7): 1594-1606. DOI: 10.1093/brain/awf150.

Ming X, O'Connor M, Bandari S, He W, Brewer G (2016). The utility of MRI in children with autism spectrum disorder. Autism Open Access 6: 164. DOI: 10.4172/2165-7890.1000164.

Mulligan CK, Trauner DA (2014). Incidence and behavioral correlates of epileptiform abnormalities in autism spectrum disorders. J Autism Dev Disord 44(2): 452-458. DOI: 10.1007/s10803-0131888-6.

Nacewicz BM, Dalton KM, Johnstone T, Long MT, McAuliff EM, Oakes TR, et al. (2006). Amygdala volume and nonverbal social impairment in adolescent and adult males with autism. Arch Gen Psychiatry 63(12): 1417-1428. DOI: 10.1001/ archpsyc.63.12.1417.

NICE - National Institute for Health and Care Excellence (2011). Autism diagnosis in children and young people. NICE clinical guideline 128. Leicester: British Psychological Society.

Ozonoff S, Iosif AM (2019). Changing conceptualizations of regression: what prospective studies reveal about the onset of autism spectrum disorder. Neurosci Biobehav Rev 100: 296-304. DOI: 10.1016/j.neubiorev.2019.03.012.

Ozonoff S, Gangi D, Hanzel EP, Hill A, Hill MM, Miller M, et al. (2018). Onset patterns in autism: variation across informants, methods, and timing. Autism Res 11(5): 788-797. DOI: 10.1002/ aur.1943.

Pearson N, Charman T, Happe F, Bolton PF, McEwen FS (2018). Regression in autism spectrum disorder: reconciling findings from retrospective and prospective research. Autism Res 11(12): 1602-1620. DOI: 10.1002/aur.2035.

Redcay E (2008). The superior temporal sulcus performs a common function for social and speech perception: implications for the emergence of autism. Neurosci Biobehav Rev 32(1): 123-142. DOI: 10.1016/j.neubiorev.2007.06.004.

Rogers SJ, DiLalla DL (1990). Age of symptom onset in young children with pervasive developmental disorders. J Am Acad Child Adolesc Psychiatry 29(6): 863-872. DOI: 10.1097/00004583199011000-00004.

Rojas DC, Peterson E, Winterrowd E, Reite ML, Rogers SJ, Tregellas JR (2006). Regional gray matter volumetric changes in autism associated with social and repetitive behavior symptoms. BMC Psychiatry 13(6): 56. DOI: 10.1186/1471-244X-6-56.

Schopler E, Reichler RJ, DeVellis RF, Daly K (1980). Toward objective classification of childhood autism: childhood autism rating scale (CARS). J Autism Dev Disord 10(1): 91-103. DOI: 10.1007/ BF02408436.

Sears LL, Vest C, Mohamed S, Bailey J, Ranson BJ, Piven J (1999). An MRI study of the basal ganglia in autism. Prog Neuropsychopharmacol Biol Psychiatry 23(4): 613-624. DOI: 10.1016/s0278-5846(99)00020-2.

Shaw CM, Alvord EC (1974). Subependymal germinolysis. Arch Neurol 31(6): 374-381. DOI: 10.1001/ archneur.1974.00490420040003.

Shevell MI, Majnemer A, Rosenbaum P, Abrahamowicz M (2001). Etiologic yield of autistic spectrum disorders: a prospective study. J Child Neurol 16(7): 509-512. DOI: 10.1177/088307380101600710.

Steiner CE, Guerreiro MM, Marques-de-Faria AP (2003). Genetic and neurological evaluation in a sample of individuals with pervasive developmental disorders. Arq Neuropsiquiatr 61(2A): 176-180. DOI: $10.1590 / \mathrm{s} 0004-282 \times 2003000200003$.

The International Classification of Diseases, 10th revision (1996). [Mezinárodní klasifikace nemocí, 10. revize]. Duševní poruchy a poruchy chování. Diagnostická kritéria pro výzkum. Prague: Psychiatrické centrum.

Tolbert L, Brown R, Fowler P, Parsons D (2001). Brief report: lack of correlation between age of symptom onset and contemporaneous presentation. J Autism Dev Disord 31(2): 241-245. DOI: 10.1023/A:1010763502253.

Tuchman R (2017). What is the relationship between autism spectrum disorders and epilepsy? Semin Pediatr Neurol 24(4): 292-300. DOI: 10.1016/j.spen.2017.10.004.

Tuchman RF, Rapin I (1997). Regression in pervasive developmental disorders: seizures and epileptiform electroencephalogram correlates. Pediatrics 99(4): 560-566. DOI: 10.1542/ peds.99.4.560.

Viscidi EW, Triche EW, Pescosolido MF, McLean RL, Joseph RM, Spence SJ, Morrow EM (2013). Clinical characteristics of children with autism spectrum disorder and co-occurring epilepsy. PLoS One 8(7): e67797. DOI: 10.1371/journal.pone.0067797.

Volkmar F, Siegel M, Woodbury-Smith M, King B, McCracken J, State M; American Academy of Child and Adolescent Psychiatry (AACAP) Committee on Quality Issues (CQI) (2014). Practice parameter for the assessment and treatment of children and adolescents with autism spectrum disorder. J Am Acad Child Adolesc Psychiatry 53(2): 237-257. DOI: 10.1016/j. jaac.2013.10.013.

Wegiel J, Kuchna I, Nowicki K, Imaki H, Wegiel J, Marchi E, et al. (2010). The neuropathology of autism: defects of neurogenesis and neuronal migration, and dysplastic changes. Acta Neuropathol 119(6): 755-770. DOI: 10.1007/s00401-010-0655-4.

Werner E, Dawson G, Munson J, Osterling J (2005). Variation in early developmental course in autism and its relation with behavioral outcome at 3-4 years of age. J Autism Dev Disord 35(3): 337-350. DOI: 10.1007/s10803-005-3301-6.

Yasuhara A (2010). Correlation between EEG abnormalities and symptoms of autism spectrum disorder (ASD). Brain Dev 32(10): 791-798. DOI: 10.1016/j.braindev.2010.08.010.

Zeglam AM, Al-Ogab MF, Al-Shaftery T (2015). MRI or not to MRI! Should brain MRI be a routine investigation in children with autistic spectrum disorders? Acta Neurol Belg 115(3): 351-354. DOI: 10.1007/s13760-014-0384-x. 